\title{
INOVASI PEMANFAATAN ABU SEKAM DARI PENGUSAHA BATU BATA UNTUK MENINGKATKAN PRODUKSI TANAMAN PADI GUNA MENUNJANG PEMBERDAYAAN PETANI
}

\author{
Suryono $^{1)}$, Suwarto ${ }^{1)}$ \\ ${ }^{1)}$ Program Studi Ilmu Tanah, Fakultas Pertanian, Universitas Sebelas Maret \\ email: suryono_uns@yahoo.com
}

\begin{abstract}
Rice husk ash is now mostly used as rub ash. Rice husk ash contains very high silicate that is needed by cereal crops, especially rice plants. The purpose of this study to examine the use of rice husk ash in increasing the production of rice plants, that can be used to support the empowerment of farmers. The research method using field trials with Randomized Complete Block Design (RCBD) consisting of one factor (husk ash) and 8 levels ie $I_{0}(0 \mathrm{~kg}), I_{1}(100 \mathrm{~kg} / \mathrm{ha}), I_{2}(200 \mathrm{~kg} / \mathrm{ha}), I_{3}(300 \mathrm{~kg} / \mathrm{ha}), I_{4}(400 \mathrm{~kg}$ / ha), $I_{5}(500 \mathrm{~kg} / \mathrm{ha}), I_{6}(600 \mathrm{~kg} / \mathrm{ha}), I_{7}(700 \mathrm{~kg} / \mathrm{ha})$ were repeated three times. The results showed that rice husk ash can be used to increase the production of rice plants, that can be used as an empowering farmers. The highest results of this study are: the number of productive tillers per clump 24.81, grain weight per clump $139.67 \mathrm{~g}$, grain weight per plot $3051 \mathrm{~g}$ and grain production 10.17 tons / ha in treatment with husk ash $500 \mathrm{~kg} / \mathrm{ha}$. The farmers in the surrounding areas are very interested in using.
\end{abstract}

Keywords: farmers, husk ash, innovation, the production of rice crops

\section{PENDAHULUAN}

Abu sekam padi saat ini kebanyakan hanya digunakan sebagai abu gosok. Abu sekam padi mengandung silikat $87 \%$ sampai 90\% (Mukhlis, 2011). Untuk tanaman padi unsur silikat termasuk unsur hara esensial

Unsur hara silikat bagi tanaman padi dapat berperan sebagai stimulator fotosintesis dan translokasi karbon dioksida (Yukamgo dan Yuwono, 2007). Unsur hara silikat terakumulasi pada daun yang dapat berfungsi menjaga daun tetap tegak dan segar yang dapat membantu dalam penangkapan cahaya sinar matahari dalam proses fotosintesis dan translokasi $\mathrm{CO}_{2}$ ke dalam malai (Fitria, 2010). Unsur silikat juga dapat mengu-rangi cekaman abiotik, yang diantarannya suhu, radiasi cahaya, dan kekeringan yang dapat juga meningkatkan resistensi tanaman terhadap cekaman biotik dan serangan penyakit disebabkan karena unsur hara Si juga dapat memperkuat jaringan tanaman.

Ketersediaan unsur hara silikat yang cukup dalam tanah dapat meningkatkan ketahanan tanaman terhadap ketidak seimbangan unsur hara seperti halnya kekurangan dan kelebihan $\mathrm{P}$, kelebihan Nitrogen, serta keracunan $\mathrm{Na}, \mathrm{Fe}$, dan $\mathrm{Mn}$ serta Al. Kelebihan unsur $\mathrm{N}$ dapat menyebabkan daun menjadi lunak sehingga penyerapan cahaya matahari dalam proses fotosintesis kurang baik. Dengan adanya unsur hara yang cukup proses fotosintesis akan maksimal atau baik.

Unsur hara silikat juga dapat menggantikan posisi fiksasi $\mathrm{P}$ oleh Alumunium dan Besi sehingga $\mathrm{P}$ menjadi lebih tersedia bagi tanaman. Ketersediaan unsur hara fosfor dalam tanah dipengaruhi unusr Fe dan Mn. Ketersediaan unsur P dalam tanah akan berkurang bila konsentrsi Besi dan Mangaan.

Ketersediaan silikat yang cukup dapat menekan unsur hara Besi dan Mangaan dalam tanah sehingga Fosfor menjadi lebih tersedia selain itu suplai unsur hara silikat dapat meningkatkan translokasi P ke malai sehingga peran unsur hara fosfor lebih optimal bagi tanaman. Toksisitas natirum dapat dikurangi dengan menurunkan laju respirasi bila unsur silikat cukup bagi tanaman sehingga mencegah keracunan Na pada tanaman.

Berdasarkan fungsi tersebut di atas maka unsur hara silikat mutlak dibutuhkan tanaman. Informasi tentang unsur hara silikat di tingkat petani sangat miskin, belum banyak informasi yang diberikan oleh pakar kepada para petani (Soemartono et al. 1994).

Berdasarkan dari permasalah tersebut diatas maka perlu inovasi pemanfaatan abu sekam untuk meningkatkan produksi tanaman 
padi yang dapat digunakan sebagai penunjang pemberdayaan petani.

\section{METODE PENELITIAN}

Penelitian dilaksanakan di Dukuh Gunung Wijil Desa Ngringo, Kecamatan Jaten, Kabupaten Karanganyar, Jawa Tengah. Metode penelitian menggunakan uji lapang dengan Rancangan Acak Kelompok Lengkap (RAKL) yang terdiri dari 1 faktor (abu sekam) dan 8 taraf yaitu $\mathrm{I}_{0}(0 \mathrm{~kg}), \mathrm{I}_{1}(100 \mathrm{~kg} \mathrm{ha}), \mathrm{I}_{2}$ $(200 \mathrm{~kg} / \mathrm{ha}), I_{3}(300 \mathrm{~kg} / \mathrm{ha}), I_{4}(400 \mathrm{~kg} / \mathrm{ha}), I_{5}$ $(500 \mathrm{~kg} / \mathrm{ha}), I_{6}(600 \mathrm{~kg} / \mathrm{ha}), I_{7}(700 \mathrm{~kg} / \mathrm{ha})$ diulang 3 kali.

Parameter yang diukur dan diamati adalah tinggi tanaman, jumlah anakan per rumpun, jumlah anakan per rumpun, berat gabah per rumpun, dan berat gabah per petak.

Analisis tanah awal meliputi $\mathrm{pH}, \mathrm{N}$ total, $\mathrm{P}$ tersedia, $\mathrm{K}$ tersedia, KPK, KB dan $\mathrm{Si}$.

\section{HASIL DAN PEMBAHASAN}

\section{Analisis tanah awal}

Tabel 1. Analisis tanah awal

\begin{tabular}{llrll}
\hline No & $\begin{array}{l}\text { Macam } \\
\text { Analisis }\end{array}$ & Hasil & Satuan & Harkat \\
\hline 1 & pH & 8,01 & -- & $\begin{array}{l}\text { Agak } \\
\text { alkalis }\end{array}$ \\
2 & N total & 0,23 & $\%$ & Sedang \\
3 & P tersedia & 7,10 & ppm & Rendah \\
4 & K tersedia & 0,20 & me $100 \mathrm{~g}^{-1}$ & Rendah \\
5 & KPK & 30,75 & ${\mathrm{me} 100 \mathrm{~g}^{-1}}^{\text {Tinggi }}$ \\
6 & KB & 69,99 & $\%$ & Tinggi \\
7 & Si & 0,050 & $\%$ & Rendah \\
\hline
\end{tabular}

Menurut Munir, 1996; Lopulisa, 2004 tanah Grumusol memiliki sifat $\mathrm{pH}$ agak alkalis (7,6-8,5), $\mathrm{N}$ total sedang $(0,21-0,50 \%), \mathrm{P}$ tersedia rendah $(5-7 \%), \mathrm{K}$ tersedia rendah $(0,1-$

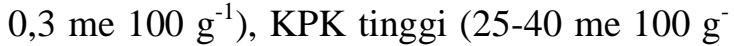
$\left.{ }^{1}\right)$, kejenuhan basa tinggi (61-80\%). Sedangkan menurut Chairunnisa, Hanum, \& Mukhlis, 2013; Djajadi, 2013; Wogo, Segu, \& Ola, 2011 tanah yang kandungan Si kurang dari $0,06 \%$ termasuk rendah.

\section{Pertumbuhan tanaman}

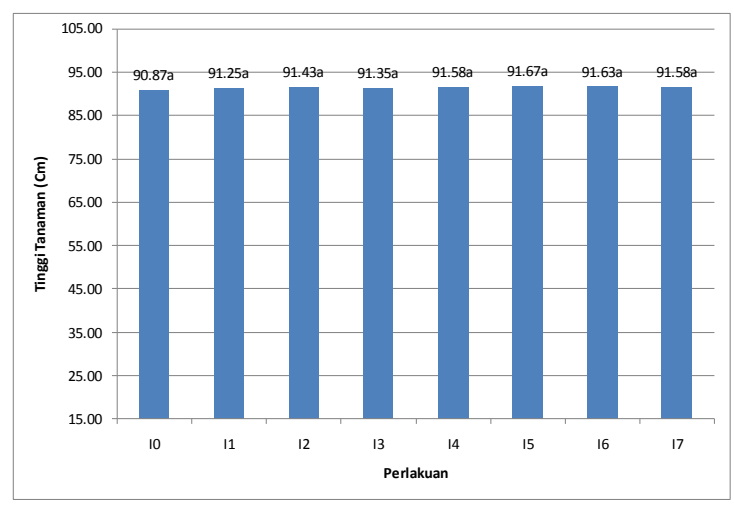

Gambar 1. Tinggi tanaman

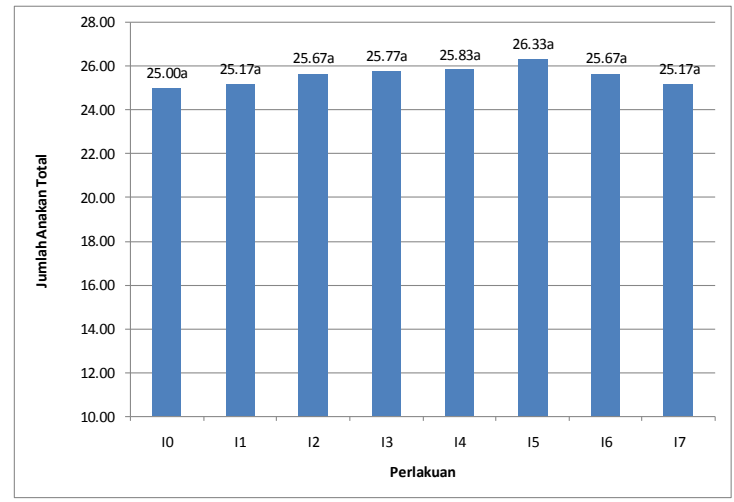

Gambar 2. Jumlah anakan total

Dari hasil analisis pertumbuhan tanaman (tinggi tanaman dan jumlah anakan total) yang diwujudkan dalam gambar (Gambar 1 dan Gambar 2), pemberian silikat semuanya tidak berbeda nyata. Hal ini disebabkan karena kandungan $\mathrm{N}$ total sedang $(0,25 \%)$, KPK tinggi (30,75 $\left.100 \mathrm{~g}^{-1}\right)$, kejenuhan basa tinggi $(69,99 \%)$ secara minimum sudah mencukupi untuk pertumbuhan tanaman.

\section{Hasil tanaman}

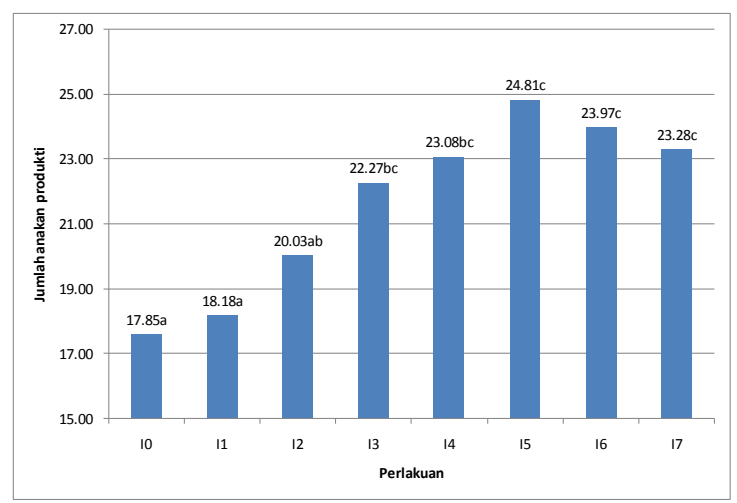

Gambar 3. Jumlah anakan produktif 


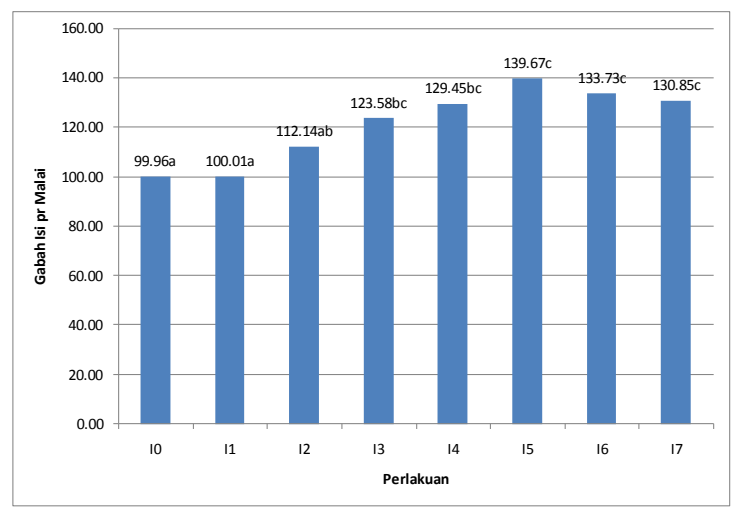

Gambar 4. Berat gabah per rumpun

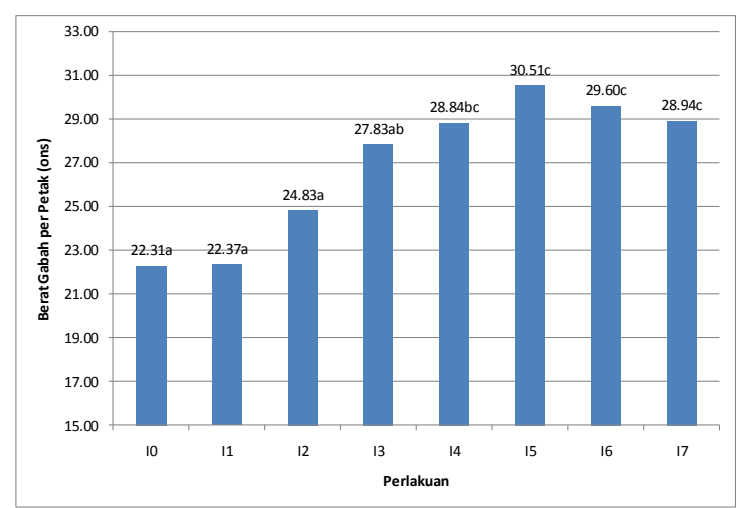

Gambar 5. Berat gabah per plot

Pemberian silikat berpengaruh nyata tehadap produksi tanaman yang meliputi jumlah anakan produktif, berat gabah per rumpun, dan berat gabah per plot yang diwujudkan dalam gambar (Gambar 3, Gambar 4 dan Gambar 5). Pemberian silikat semuanya berpengaruh terhadap peningkatan hasil. Hal ini disebabkan karena kandungan unsur hara $\mathrm{P}$ rendah, dan silikat mampu meningkatkan ketersediaan unsur hara $\mathrm{P}$ dalam tanah. Semakin tinggi dosis abu sekam yang ditambahkan sampai batas tertentu dalam tanah maka semakin meningkatkan ketersediaan $\mathrm{P}$, sedangkan unsur hara $\mathrm{P}$ berfungsi dalam fase generatif (produksi).

\section{Tanggapan Petani}

Lokasi penelitian berada di lahan petani yang menanam padi. Dari pengamatan petani pada sisi visual (hasil tanaman padi saat pertumbuhan dan saat panen) sangat tertarik karena terlihat sangat nyata secara visual. Secara aktual peningkatan anakan produktif mencapai 38,98\% (dari 17,85 anakan menjadi 24,81 anakan), hasil per petak (ukuran petak $2 \times 1,5 \mathrm{~m}$ ) naik $36,80 \%$ (dari 22,31 ons menjadi 30,51 ons ekuivalen dengan 7,44 ton/ha menjadi 10,17 ton/ha)
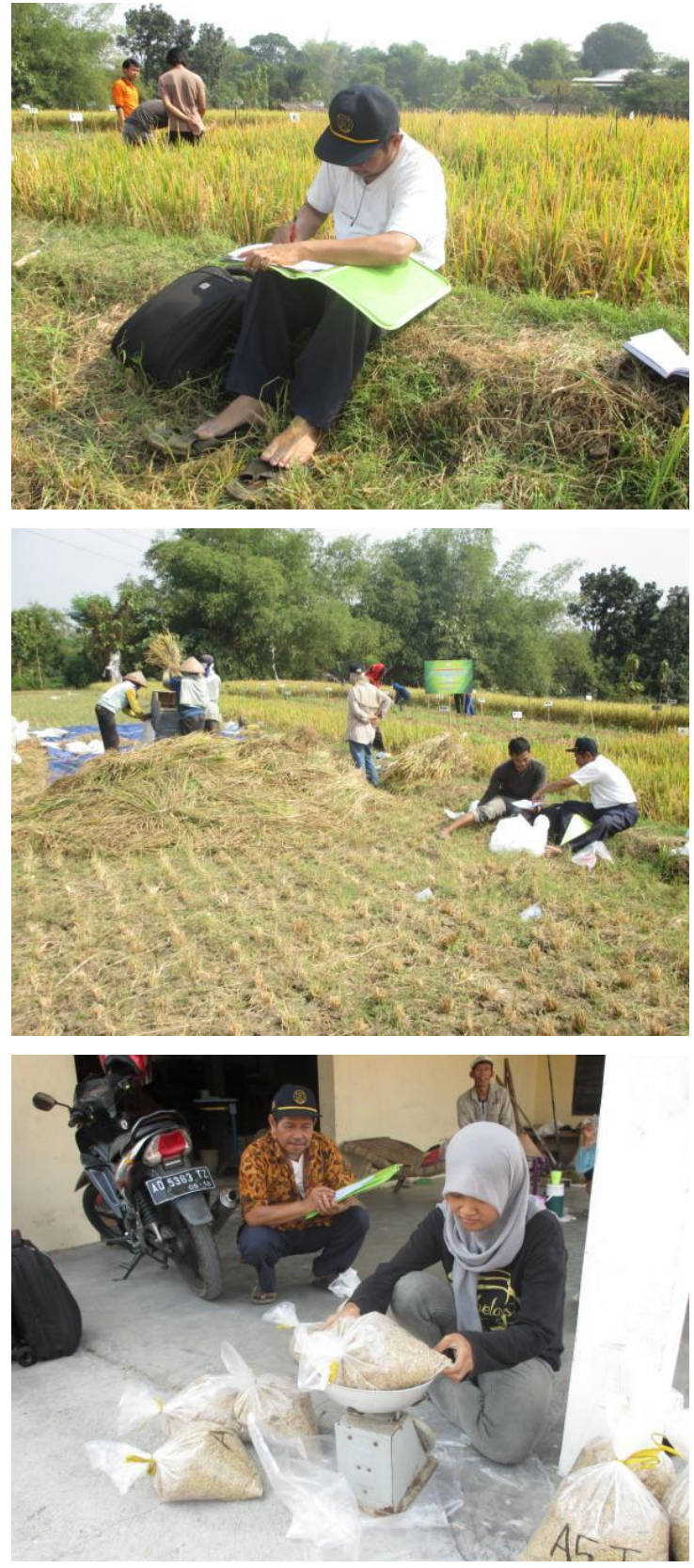

\section{KESIMPULAN}

Hasil penelitian menunjukkan bahwa abu sekam padi dapat dimanfaatkan untuk meningkatkan produksi tanaman padi yang dapat digunakan sebagai pemberdayaan petani. Hasil tertinggi dari penelitian ini adalah: jumlah anakan produktif per rumpun 24,81, berat gabah per rumpun $139,67 \mathrm{~g}$, berat gabah per petak $3.051 \mathrm{~g}$ dan produksi gabah 10,17 ton / ha pada perlakuan abu sekam $500 \mathrm{~kg} / \mathrm{ha}$. Petani-petani yang ada di sekitarnya sangat tertarik menggunakan. 


\section{DAFTAR PUSTAKA}

Chairunnisa, Cici, Hamidah Hanum, Mukhlis Mukhlis. 2013. Peran beberapa bahan silikat $(\mathrm{Si})$ dan pupuk fosfat $(\mathrm{P})$ dalam memperbaiki sifat kimia tanah andisol dan pertumbuhan tanaman. Agroekoteknologi 1.3.

Djajadi. 2013. Silika (Si): Unsur hara penting dan menguntungkan bagi tanaman tebu (Saccharum officinarum L.). Perspektif Vol. 12 No. 1/Juni 2013. Hlm 47-55.

Fitria, S. 2010. Perubahan Sifat Kimia tanah Andisol Akibat Pemberian Bahan Silikat. Universitas Sumatera Utara ; Fakultas Pertanian.

Lopulisa. 2004. Dasar-Dasar Ilmu Tanah. PT. Rajagara Findo Persada: Jakarta.
Mukhlis. 2011. Tanah Andisol Genesis, Klasifikasi, Karakteristik, Penyebaran dan Analisis. USU Press. Medan.

Munir, M. 1996. Tanah Ultisol - Tanah Ultisol Di Indonesia. Pustaka Jaya. Jakarta.

Soemartono, Bahrin S, Harjono. 1994. Bercocok Tanam Padi. Yasaguna. Jakarta.

Wogo, H. E., Segu, J. O., Ola, P. 2011, Sintesis silika gel terimobilisasi ditizon melalui proses sol gel. J. Sains dan Terapan Kimia, 5, 84-95.

Yukamgo, E., N. W. Yuwono. 2007. Peran silikon sebagai unsur bermanfaat pada tanaman tebu. Jurnal Ilmu Tanah dan Lingkungan Vol. 7 : 2 (103-116). 